Int. J. Electrochem. Sci., 15 (2020) 12264 - 12280

\title{
Study on the Hydration Processes of High Belite Sulphoaluminate Cement using Electrochemical Impedance Spectroscopy
}

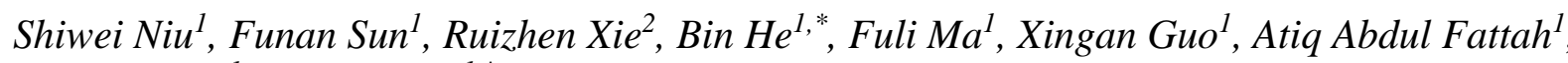 \\ Xingyi Wang ${ }^{l}$, Pengju Han ${ }^{1, *}$ \\ ${ }^{1}$ College of Civil Engineering, Taiyuan University of Technology, Taiyuan, 030024, China \\ ${ }^{2}$ Mechanics Institute, Jinzhong University, Jinzhong, 030619, China \\ *E-mail: hebin@tyut.edu.cn, 13834569544@163.com
}

doi: $10.20964 / 2020.12 .35$

Received: 2 August 2020 / Accepted: 28 September 2020 / Published: 31 October 2020

This paper aimed to use electrochemical impedance spectroscopy (EIS) to investigate the hydration process of a new generation of cement, as this method has the characteristics of providing energy savings and being environment friendly, and use X-ray diffraction (XRD) to analyse the composition of hydration products at different hydration times. The experimental results suggested that the Nyquist plots of different hydration times had their own distinctive features. In addition, the used equivalent circuit model could provide a good explanation for the experimental phenomenon. The impedance parameters $\mathrm{R}_{\mathrm{CCP}}$ and $\mathrm{R}_{\mathrm{CP}}$ increased with increasing hydration time, but the parameter $\mathrm{C}_{\mathrm{DP}}$ decreased. Correspondingly, the effect of the water-cement ratio on these parameters was completely opposite of that of the hydration time. Furthermore, the results of XRD analysis showed that AFt was the main hydration product in the early stage, and the hydration of $\mathrm{C}_{2} \mathrm{~S}$ was the main process in the late stage.

Keywords: hydration process; X-ray diffraction; microstructure; electrochemical impedance spectroscopy

\section{$\underline{\text { FULL TEXT }}$}

(C) 2020 The Authors. Published by ESG (www.electrochemsci.org). This article is an open access article distributed under the terms and conditions of the Creative Commons Attribution license (http://creativecommons.org/licenses/by/4.0/). 